\title{
PD-L1 expression is associated with advanced non-small cell lung cancer
}

\author{
ZHIQUAN CHEN ${ }^{1-3}$, JIANDONG MEI $^{3-5}$, LUNXU LIU $^{4,5}$, GUOCHEN WANG $^{2}$, ZUOSHENG LI $^{2}$, \\ JINGPU HOU ${ }^{2}$, QIUYANG ZHANG ${ }^{3}$, ZONGBING YOU ${ }^{3}$ and LIU ZHANG ${ }^{1,6}$
}

\author{
${ }^{1}$ Department of Surgery, The Fourth Hospital of Hebei Medical University, Shijiazhuang, Hebei 050017; \\ ${ }^{2}$ Department of Thoracic Surgery, Affiliated Hospital of North China University of Science and Technology, \\ Tangshan, Hebei 063000, P.R. China; ${ }^{3}$ Department of Structural and Cellular Biology, Tulane University, New Orleans, \\ LA 70112, USA; ${ }^{4}$ Department of Thoracic Surgery, West China Hospital, Sichuan University; \\ ${ }^{5}$ Western China Collaborative Innovation Center for Early Diagnosis and Multidisciplinary Therapy of Lung Cancer, \\ Sichuan University, Chengdu, Sichuan 610041; ${ }^{6}$ Department of Surgery, \\ Affiliated Hospital of North China University of Science and Technology, Tangshan, Hebei 063000, P.R. China
}

Received August 24, 2015; Accepted May 16, 2016

DOI: $10.3892 / 01.2016 .4741$

\begin{abstract}
Lung cancer is the most common cause of cancer-associated mortalities worldwide. Novel immunotherapies have been developed to improve the clinical outcomes of non-small cell lung cancer (NSCLC). Antibodies against programmed cell death protein 1 (PD-1) and programmed cell death protein 1 ligand 1 (PD-L1) have been tested in clinical trials, and anti-PD-1 antibody has been approved for the treatment of NSCLC. The aim of the present study was to assess expression of PD-1,PD-L1 and programmed cell death protein 1 ligand 2 (PD-L2) in 48 patients with NSCLC, using immunohistochemical staining. The results found that $35.4 \%$ (17/48) of patients were positive for PD-1 expression, 64.6\% (31/48) were positive for PD-L1 expression and $45.8 \%$ (22/48) were positive for PD-L2 expression. Neither PD-1 nor PD-L2 expression was associated with gender, histology, differentiation status, tumor stage or lymph node metastasis. PD-L1 expression was not associated with gender, histology, differentiation status or lymph node metastasis; however, PD-L1 expression was significantly increased in stage III NSCLC (85.7\% PD-L1+) compared with stage I/II NSCLC (55.9\% PD-L1+) ( $\mathrm{P}=0.049)$.
\end{abstract}

Correspondence to: Dr Liu Zhang, Department of Surgery, The Fourth Hospital of Hebei Medical University, 12 Jiankang Road, Shijiazhuang, Hebei 050017, P.R. China

E-mail: zhliu130@sohu.com

Dr Zongbing You, Department of Structural and Cellular Biology, Tulane University, 1430 Tulane Avenue, New Orleans, LA 70112, USA

E-mail: zyou@tulane.edu

Key words: lung cancer, programmed cell death protein 1, programmed cell death protein 1 ligand 1, programmed cell death protein 1 ligand 2, immunohistochemistry

\section{Introduction}

Lung cancer is the most common cause of cancer-associated mortalities worldwide (1). The American Cancer Society estimated that there would be $\sim 221,200$ novel cases and $\sim 158,040$ mortalities caused by lung cancer in the USA in $2015(1,2)$. Lung cancer is the second most common malignancy and the most common cause of cancer-associated mortality in American men and women (1). In China, novel cases and lung cancer-associated mortalities were estimated to be 536,407 and 475,768, respectively, in 2005 (2). Globally, it has been estimated that there were 1,824,700 novel cases and 1589,900 lung cancer-associated mortalities in 2012 (3).

Currently, surgical resection remains the standard of care for the majority of patients with non-metastatic non-small cell lung cancer (NSCLC). Cancer immunotherapy has recently received attention (4), since the United States Food and Drug Administration (FDA) approved Provenge ${ }^{\circledR}$ (sipuleucel-T) for the treatment of metastatic castration-resistant prostate cancer and Yervoy ${ }^{\circledR}$ (ipilimumab) for the treatment of metastatic melanoma $(5,6)$. Inhibitors of the programmed cell death protein 1 (PD-1), an immunosuppressive checkpoint protein, and the programmed cell death protein 1 ligand 1 (PD-L1) and ligand 2 (PD-L2), have demonstrated positive outcomes in the treatment of cancers, including lung cancer, in clinical trials (7).

A phase I clinical trial reported objective responses in approximately $1 / 4$ to $1 / 5$ of patients with NSCLC, melanoma and renal-cell cancer, who were treated with anti-PD-1 antibodies (8). Another phase I clinical trial reported objective response rates of 6-17\% and a stabilization of disease at rates of $12-41 \%$ at 24 weeks in patients with advanced cancers, including NSCLC, melanoma and renal-cell cancer, who were treated with anti-PD-L1 antibodies (9). Three patients sustained long-term partial or complete response in 16 months to 3 years following treatment (10). Subsequent studies showed that anti-PD-1 antibody (lambrolizumab) 
produced a response rate of $\sim 38 \%$ in melanoma patients, with or without prior ipilimumab treatment (11). A combination of anti-PD-1 antibody (nivolumab) and ipilimumab produced a $53 \%$ objective response in the patients with advanced melanoma (12). A phase III trial showed that anti-PD-1 antibody (pembrolizumab, also called lambrolizumab or MK-3475) produced a significantly better response rate $(\sim 33 \%)$ compared with ipilimumab $(11.9 \%$; $\mathrm{P}<0.001)$ in the treatment of advanced melanoma (13). A recent phase I trial showed that pembrolizumab produced an objective response rate of $19.4 \%$ in 495 patients with NSCLC. The median duration of progression-free survival was 3.7 months and the median duration of overall survival was 12.0 months (14). Therefore, on September 4, 2014, the FDA granted accelerated approval to the anti-PD-1 antibody pembrolizumab (Keytruda ${ }^{\circledR}$; Merck \& Co, Inc., Whitehouse Station, NJ, USA) for the treatment of patients with unresectable or metastatic melanoma and disease progression following ipilimumab and, if B-Rapidly Accelerated Fibrosarcoma (BRAF) V600 mutation positive, a BRAF inhibitor such as vemurafenib, sorafenib or dabrafenib. The FDA also approved nivolumab (Opdivo ${ }^{\circledR}$; Bristol-Myers Squibb Company, Princeton, NJ, USA) for the treatment of patients with unresectable or metastatic melanoma and disease progression following ipilimumab and, if BRAF V600 mutation positive, a BRAF inhibitor for the treatment of patients with metastatic squamous NSCLC with progression during or following platinum-based chemotherapy, on December 22, 2014 and March 4, 2015, respectively. FDA assigned a priority review designation to pembrolizumab (Keytruda ${ }^{\circledR}$ ) as a treatment for patients with advanced NSCLC and a final approval decision will be made in the future. Anti-PD-L1 antibody (MPDL3280A; Genentech; Roche, South San Francisco, CA, USA) showed responsive rates of $13-26 \%$ in solid tumors, including NSCLC (15). On February 2, 2015, the FDA gave MPDL3280A a breakthrough therapy designation for the treatment of PD-L1-positive NSCLC that has progressed during or following platinum-based chemotherapy, as well as a targeted therapy for patients with epidermal growth factor receptor (EGFR)-positive or anaplastic lymphoma kinase (ALK)-positive tumors. MPDL3280A is currently undergoing phase II and III trials to obtain FDA approval (16).

PD-1 was originally identified by Ishida et al (17) in search of genes responsible for programmed cell death. The study cloned a gene encoding a protein with 288 amino acids, which was activated during programmed cell death; therefore, the protein was named PD-1 (17). Disruption of the PD-1 gene led to development of lupus-like arthritis and glomerulonephritis, indicating that PD-1 is a negative regulator of immune responses $(18,19)$. Honjo and Freeman et al $(20)$ collaboratively identified PD-L1, which is identical to B7-H1 reported by Dong et al (21). Latchman et al (22) further identified a second PD-1 ligand PD-L2, which is identical to B7-DC (23). The binding of PD-1 by PD-L1 and PD-L2 is now known to inhibit $\mathrm{T}$ cell receptor-mediated lymphocyte proliferation and cytokine secretion, thus suppressing immune responses (24). In the tumor microenvironment, the PD-1-PD-L1/L2 pathway is upregulated, resulting in the immune evasion of tumor cells $(22,25)$. Therefore, the antibodies against PD-1, PD-L1 and likely PD-L2 may block the immune evasion response and induce tumor regression.
PD-1, a negative costimulatory receptor, is primarily expressed on the cellular surface of activated T cells $(26,27)$. PD-L1 is expressed by tumor cells and tumor-infiltrating immune cells, including macrophages, dendritic cells and T cells (15). PD-L1 and PD-L2 mRNAs are expressed in the human heart, placenta, spleen, lymph nodes and thymus tissues. In addition, PD-L2 messenger RNA (mRNA), but not PD-L1 mRNA, is expressed in the human lung, liver, smooth muscle and pancreas tissues (22). In a cohort of 824 NSCLC patients, $\geq 50 \%$ of tumor cells stained positive for PD-L1 in $23.2 \%$ of patients, $1-49 \%$ of tumor cells stained positive for PD-L1 in $37.6 \%$ of patients and $<1 \%$ of tumor cells stained positive for PD-L1 in $39.2 \%$ of patients (14). The objective response rate (ORR) to pembrolizumab treatment is positively associated with the percentage of tumor cells with membranous PD-L1 staining, for example: Patients that were < $1 \%$ PD-L1+ exhibited an $8.1 \%$ ORR; patients that were $1-24 \%$ PD-L1+ exhibited a $12.9 \%$ ORR; patients that were $25-49 \%$ PD-L1+ exhibited a $19.4 \%$ ORR; patients that were $50-74 \%$ PD-L1+ exhibited a $29.6 \%$ ORR; and patients that were $75-100 \%$ PD-L1+ exhibited a $45.4 \%$ ORR (14). In contrast, in a cohort of 272 squamous NSCLC, the ORRs to nivolumab treatment were similar between PD-L1+ and PD-L1- tumors, namely: Patients that were <1\% PD-L1+ exhibited a 17\% ORR; patients that were $\geq 1 \%$ PD-L1+ exhibited a $17 \%$ ORR; patients that were $<5 \%$ PD-L1+ exhibited a $15 \%$ ORR; patients that were $\geq 5 \%$ PD-L1+ exhibited a $21 \%$ ORR; patients that were $<10 \%$ PD-L1+ exhibited a $16 \%$ ORR; and patients that were $\geq 10 \%$ PD-L1+ exhibited a 19\% ORR). This discrepancy may be due to the differences in sample size or antibodies. However, additional studies are required to assess expression of PD-1, PD-L1 and PD-L2 in NSCLC. Although Keytruda ${ }^{\circledR}$ and Opdivo ${ }^{\circledR}$ are not yet approved for use in China, their eventual approval is possible.

Therefore, the objective of this study was to assess expression of PD-1, PD-L1, and PD-L2 in 48 cases of NSCLC in China. We found that PD-L1, but not PD-1 or PD-L2 expression was associated with stage III NSCLC.

\section{Materials and methods}

Human lung cancer tissue samples. The present study was approved by the Institutional Review Board of The Fourth Hospital of Hebei Medical University (Shijiazhuang, China). The procedures to obtain human lung cancer tissue and follow-up information were in accordance with the Ethical Principles for Medical Research Involving Human Subjects, as formulated in the World Medical Association Declaration of Helsinki (revised 2008). All human lung cancer tissue samples were obtained from the archives of formalin-fixed, paraffin-embedded tissue blocks in the Department of Thoracic Surgery at The Fourth Hospital of Hebei Medical University (Shijiazhuang, China). The specimens were collected from surgeries performed between April 2010 and March 2013. Written informed consent was obtained from all patients prior to surgery. The patients were followed up until March 2015, through outpatient visits or correspondences to family members. In total, 48 patients were included in this retrospective study. Tumor stage was evaluated according to the Union for International Cancer Control (UICC) 7th TNM classification system and histological evaluation was based on the World Health Organization criteria (28). The clinicopathological characteristics of the patients are summarized in Table I. 
Table I. Clinicopathological characteristics of patients $(n=48)$.

\begin{tabular}{lc}
\hline Characteristic & No. of patients \\
\hline Age, years ${ }^{\mathrm{a}}$ & $59.3 \pm 7.6$ \\
Gender & 33 \\
Male & 15 \\
Female & \\
Histology & 23 \\
SCC & 25 \\
ADC & \\
Differentiation & 40 \\
Well & 8 \\
Poor & 17 \\
Tumor stage & 17 \\
I & 14 \\
II & \\
III & 30 \\
Lymph node metastasis & 18 \\
No & \\
Yes & \\
\hline Data are presented as mean \pm standard deviation. SCC, squamous \\
cell carcinoma; ADC, adenocarcinoma. \\
\hline
\end{tabular}

Immunohistochemistry. Tissue sections (4- $\mu \mathrm{m}$ thick) were baked at $60^{\circ} \mathrm{C}$ for $60 \mathrm{~min}$, deparaffinized in xylene and rehydrated through graded ethanol solutions to water. Antigens were retrieved by heating the tissue sections in $0.01 \mathrm{M}$ ethylenediaminetetraacetic acid buffer at $95^{\circ} \mathrm{C}$ for $5 \mathrm{~min}$ and then cooling down to room temperature in $20 \mathrm{~min}$. Endogenous peroxidase activity was blocked by $0.3 \% \mathrm{H}_{2} \mathrm{O}_{2}$ for $5 \mathrm{~min}$. Non-specific binding was blocked with $1.5 \%$ normal goat or horse serum (VECTASTAIN Elite ABC kit; Vector Laboratories, Burlingame, CA, USA). The sections were incubated with primary antibodies in a humid chamber at $4^{\circ} \mathrm{C}$ overnight: Rabbit anti-human PD-L1 polyclonal antibodies (catalog no., ab58810; dilution, 1:40; Abcam, Cambridge, MA, USA), rabbit anti-human PD-L2 polyclonal antibodies (catalog no., SAB3500395-100UG; dilution, 1:800; Sigma-Aldrich, St. Louis, MO, USA) and mouse anti-human cluster of differentiation (CD)279 (PD-1) purified monoclonal antibodies (catalog no., 14-9989-82; dilution, 1:25; eBioscience, Inc., San Diego, CA, USA) were used as the primary antibodies. Subsequent to being washed 3 times in phosphate-buffered saline, the sections were incubated with secondary antibodies from the VECTASTAIN Elite ABC kit for $120 \mathrm{~min}$. The color was developed using 3,3'-diaminobenzidine (DAB) substrate kit (Vector Laboratories) following the manufacturer's protocol. The sections were then counterstained with hematoxylin. Tissue sections that had previously stained positively were used as a positive control and tissue sections stained with non-immune serum rather than primary antibodies served as a negative control. Positive staining showed brown particles at the cytoplasmic membrane or in the cytoplasm. Under a microscope, 5 representative high-power (magnification, x400) fields, containing
Table II. Association between PD-1 expression and clincopathological characteristics of patients.

\begin{tabular}{|c|c|c|c|}
\hline \multirow[b]{2}{*}{ Characteristic } & \multicolumn{2}{|c|}{ PD-1 expression } & \multirow[b]{2}{*}{ P-value } \\
\hline & + & - & \\
\hline No. of patients & 17 & 31 & \\
\hline Age, years ${ }^{\mathrm{a}}$ & $58.7 \pm 8.4$ & $59.6 \pm 7.3$ & 0.667 \\
\hline \multicolumn{4}{|l|}{ Gender } \\
\hline Male & 11 & 22 & 0.654 \\
\hline Female & 6 & 9 & \\
\hline \multicolumn{4}{|l|}{ Histology } \\
\hline $\mathrm{SCC}$ & 9 & 14 & 0.606 \\
\hline $\mathrm{ADC}$ & 8 & 17 & \\
\hline \multicolumn{4}{|l|}{ Differentiation } \\
\hline Well & 16 & 24 & 0.138 \\
\hline Poor & 1 & 7 & \\
\hline \multicolumn{4}{|l|}{ Tumor stage } \\
\hline $\mathrm{I} / \mathrm{II}$ & 13 & 21 & 0.525 \\
\hline III & 4 & 10 & \\
\hline \multicolumn{4}{|c|}{ Lymph node metastasis } \\
\hline No & 12 & 18 & 0.391 \\
\hline Yes & 5 & 13 & \\
\hline
\end{tabular}

${ }^{\text {a}}$ Data presented as mean \pm standard deviation. PD-1, programmed cell death protein 1; SCC, squamous cell carcinoma; ADC, adenocarcinoma.

tumor islet cells and stroma, per tissue section were randomly selected and evaluated by two investigators (Dr Zhiquan Chen from Hebei Medical University, Shijiazhuang, China, and Dr Jiandong Mei from Sichuan University, Chengdu, China), who were blinded to the clinicopathological characteristics. An average of the scores obtained by the two examiners was used to represent each case. A two-score system based on a proportion score and an intensity score, previously described by Allred et al (29), was used. The proportion scores were assigned based on the percentage of positive staining: 0 , none; $1,<1 \% ; 2,1-10 \% ; 3,10-33.3 \% ; 4,33.3-66.7 \%$; and $5,>66.7 \%$. The intensity scores were assigned based on the estimated average staining intensity of positive staining: 0 , none; 1 , weak; 2 , intermediate; and 3, strong. The overall Allred scores (29) were the sum of the proportion score and intensity score of each case (range, 0-8).

Statistical analysis. Statistical analysis was performed using the Statistical Package for the Social Sciences (SPSS) version 16.0 for Windows (SPSS, Chicago, IL, USA). The results were presented as the mean \pm standard deviation (SD) or median and range for numerical variables. The comparison of clinicopathological characteristics between various groups was performed using the $\chi^{2}$ test. Spearman's rank correlation coefficient was calculated to reveal the correlation between PD-1, PD-L1 and PD-L2 scores. The survival time of various groups was described using Kaplan-Meier curves, and the statistical significance was analyzed using the log-rank test. $\mathrm{P}<0.05$ was considered to indicate a statistically significant difference. 
Table III. Association between PD-L2 expression and clincopathological characteristics of patients.

\begin{tabular}{lccc}
\hline & \multicolumn{2}{c}{ PD-L2 expression } & \\
\cline { 2 - 3 } Characteristic & + & - & P-value \\
\hline No. of patients & 22 & 26 & \\
Age, years & & & \\
Gender & $60.6 \pm 7.1$ & $58.2 \pm 8.0$ & 0.919 \\
Male & & & \\
Female & 15 & 18 & 0.938 \\
Histology & 7 & 8 & \\
SCC & & & \\
ADC & 10 & 13 & 0.753 \\
Differentiation & 12 & 13 & \\
Well & & & \\
Poor & 19 & 21 & 0.897 \\
Tumor stage & 3 & 5 & \\
I/II & & & \\
III & 16 & 18 & 0.791 \\
Lymph node metastasis & 8 & 6 & \\
No & 15 & 15 & 0.454 \\
Yes & 7 & 11 & \\
\hline
\end{tabular}

a Data presented as mean \pm standard deviation. PD-L2, programmed cell death protein 1 ligand 2; SCC, squamous cell carcinoma; ADC, adenocarcinoma.

\section{Results}

PD-1, PD-L1 and PD-L2 are expressed in NSCLC. Immunohistochemical staining revealed that PD-1 was expressed in the immune cells that were located mostly in the stroma of lung adenocarcinomas and squamous cell carcinomas (Fig. 1). PD-L1 and PD-L2 were expressed in the cancer cells of lung adenocarcinomas and squamous cell carcinomas (Fig. 1).

PD-L1, but not PD-1 or PD-L2, is associated with stage III lung cancer. To assess whether the expression of PD-1, PD-L1 and PD-L2 is correlated with any clinicopathological characteristics of the patients, any staining (Allred score ranges 1-8) was defined as positive $(+)$ and no staining (Allred score $=0$ ) was defined as negative (-). Analysis revealed that neither PD-1 nor PD-L2 expression was associated with the patients' gender, tumor histological types, tumor differentiation, tumor stage or status of lymph node metastasis (Tables II and III). PD-L1 expression was not associated with the patients' gender, tumor histological types, tumor differentiation or status of lymph node metastasis (Table IV). However, PD-L1 expression was associated with the tumor stage $(\mathrm{P}=0.049)$. The positive staining rate was $55.9 \%(19 / 34)$ in the stage $1 /$ II tumors, whereas it was $85.7 \%(12 / 14)$ in the stage III tumors (Table IV).

PD-1, PD-L1 and PD-L2 expression is independent of each other in lung cancer. Correlation analysis found that the expressions of PD-1, PD-L1 and PD-L2 were independent of
Table IV. Association between PD-L1 expression and clincopathological characteristics of patients.

\begin{tabular}{|c|c|c|c|}
\hline \multirow[b]{2}{*}{ Characteristic } & \multicolumn{2}{|c|}{ PD-L1 expression } & \multirow[b]{2}{*}{ P-value } \\
\hline & + & - & \\
\hline No. of patients & 31 & 17 & \\
\hline Age, years ${ }^{\mathrm{a}}$ & $60.5 \pm 6.7$ & $57.2 \pm 8.8$ & 0.164 \\
\hline \multicolumn{4}{|l|}{ Gender } \\
\hline Male & 23 & 10 & 0.272 \\
\hline Female & 8 & 7 & \\
\hline \multicolumn{4}{|l|}{ Histology } \\
\hline $\mathrm{SCC}$ & 14 & 9 & 0.606 \\
\hline $\mathrm{ADC}$ & 17 & 8 & \\
\hline \multicolumn{4}{|l|}{ Differentiation } \\
\hline Well & 24 & 16 & 0.138 \\
\hline Poor & 7 & 1 & \\
\hline \multicolumn{4}{|l|}{ Tumor stage } \\
\hline I/II & 19 & 15 & 0.049 \\
\hline III & 12 & 2 & \\
\hline \multicolumn{4}{|c|}{ Lymph node metastasis } \\
\hline No & 18 & 12 & 0.107 \\
\hline Yes & 13 & 5 & \\
\hline
\end{tabular}

aData presented as mean \pm standard deviation. PD-L1, programmed cell death protein 1 ligand 1; SCC, squamous cell carcinoma; ADC, adenocarcinoma.

Table V. Correlation between PD-1 and PD-L1 or PD-L2 expression.

\begin{tabular}{lrrr}
\hline & \multicolumn{2}{c}{ PD-1 expression } & \\
\cline { 2 - 3 } Protein & + & - & P-value \\
\hline PD-L1 & 12 & 19 & \\
+ & 5 & 12 & 0.519 \\
- & & & \\
PD-L2 & 8 & 14 & 0.900 \\
+ & 9 & 17 & \\
\hline
\end{tabular}

PD-1, programmed cell death protein 1; PD-L1/2, programmed cell death protein 1 ligand $1 / 2$.

each other. No correlation was identified between PD-1 and PD-L1 expression, PD-1 and PD-L2 expression or PD-L1 and PD-L2 expression (Fig. 2; Table V).

PD-1, PD-L1 and PD-L2 expression is not associated with the survival time in lung cancer patients. Kaplan-Meier analysis showed that PD-1, PD-L1 and PD-L2 expression was not associated with the survival time of patients with lung cancer (Fig. 3). Increased levels of PD-1 expression appeared to be inversely 


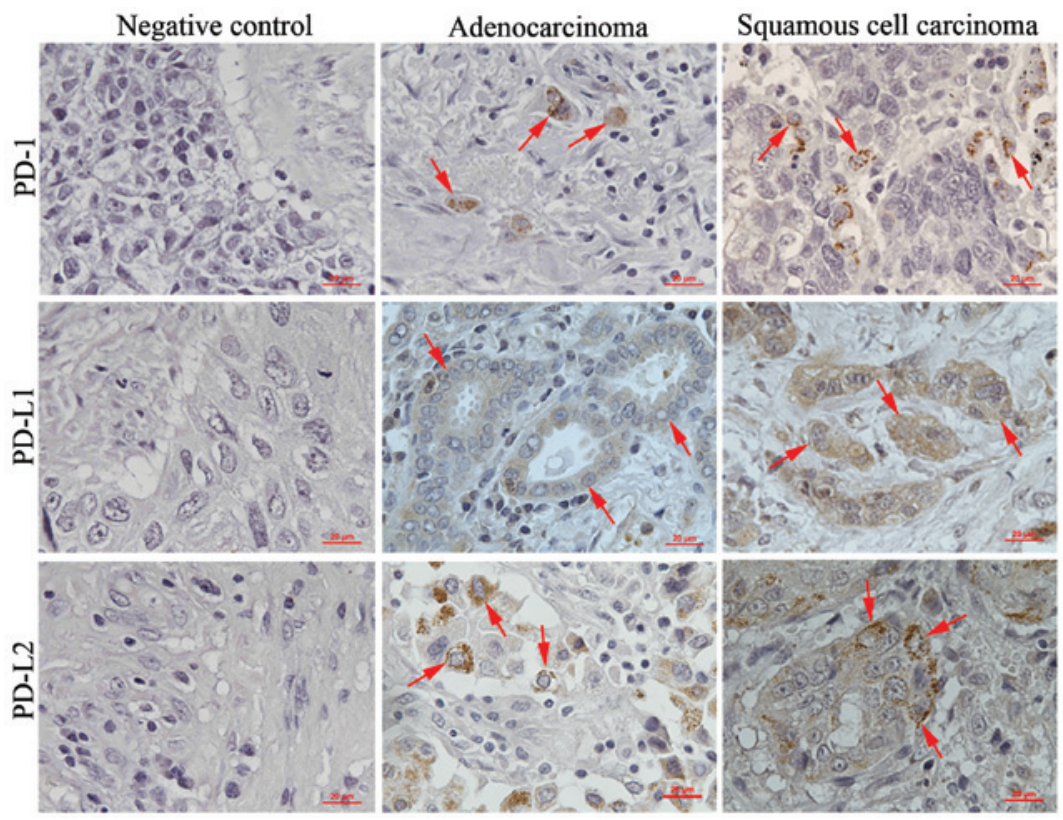

Figure 1. Representative photomicrographs of immunohistochemical staining. Arrows indicate the positively stained cells. Original magnification, $\mathrm{x} 400$. PD-1, programmed cell death protein 1; PD-L1/2, programmed cell death protein 1 ligand 1/2.
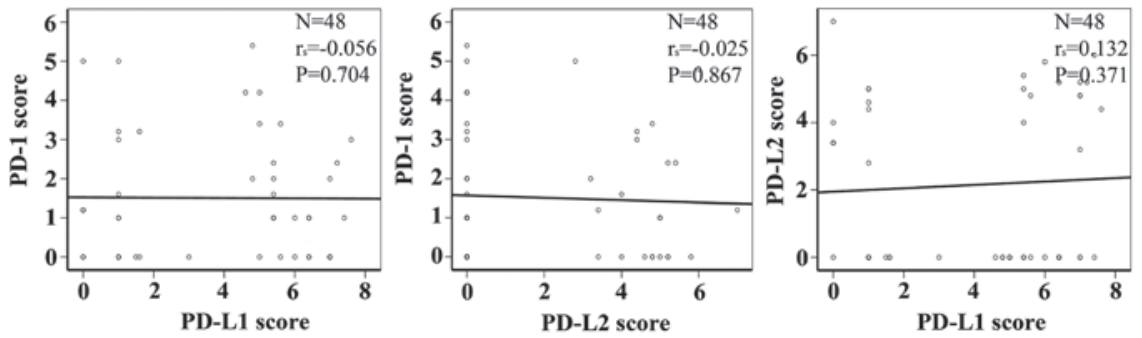

Figure 2. Correlation analysis of PD-1, PD-L1 and PD-L2 expression. The expression levels are represented by Allred scores and assessed by Spearman's rank correlation coefficient between each pair of proteins. PD-1, programmed cell death protein 1; PD-L1/2, programmed cell death protein 1 ligand $1 / 2$.
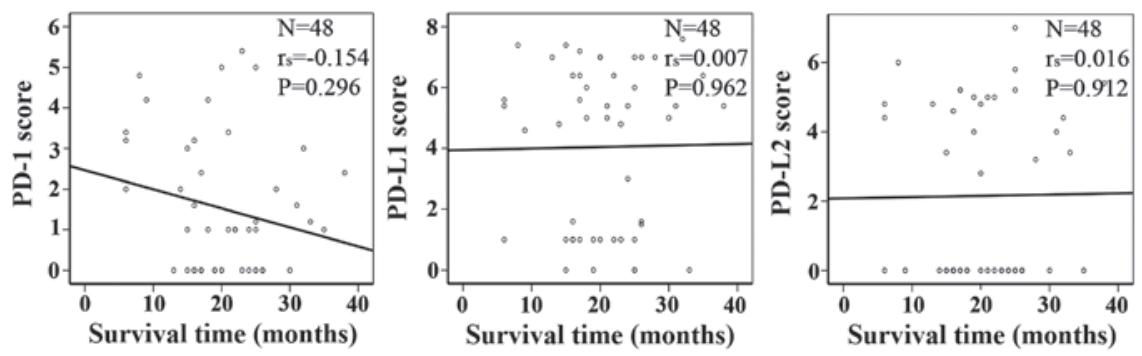

Figure 3. Correlation analysis between PD-1, PD-L1 and PD-L2 expression and the survival time of the lung cancer patients. The expression levels are represented by Allred scores and assessed by Spearman's rank correlation coefficient between the expression level and survival time. PD-1, programmed cell death protein 1; PD-L1/2, programmed cell death protein 1 ligand 1/2.
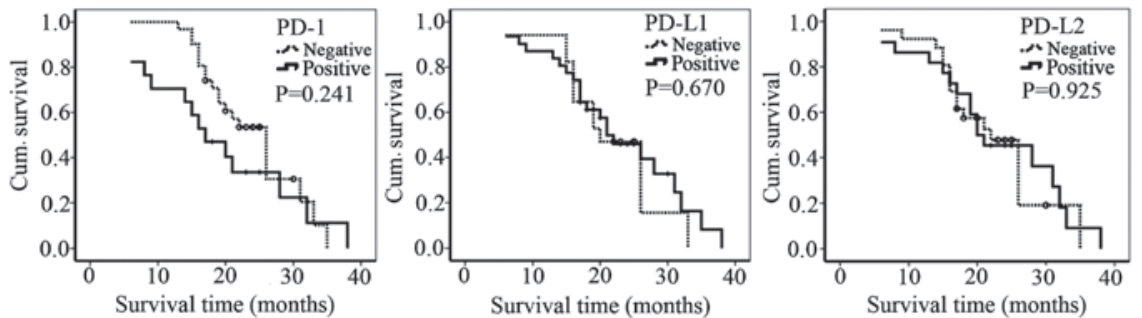

Figure 4. Kaplan-Meier curves of the lung cancer patients with positive and negative staining. The statistical significance was analyzed using the log-rank test. PD-1, programmed cell death protein 1; PD-L1/2, programmed cell death protein 1 ligand 1/2; Cum., cumulative. 
associated with the survival time; however, this result was not statistically significant (Fig. 3). In addition, the survival time of patients with tumors that were positively stained for PD-1,PD-L1 and PD-L2 expression was not significantly different from the survival time of patients with negatively stained tumors (Fig. 4).

\section{Discussion}

In the present study of a cohort of 48 patients with NSCLC, $35.4 \%$ (17/48) of patients were positive for PD-1 expression, $64.6 \%(31 / 48)$ of patients were positive for PD-L1 expression and $45.8 \%$ (22/48) of patients were positive for PD-L2 expression. Neither PD-1 nor PD-L2 expression was associated with gender, histology, differentiation status, tumor stage or lymph node metastasis. PD-L1 expression was not associated with gender, histology, differentiation status or lymph node metastasis. However, PD-L1 expression was significantly increased in stage III NSCLC (85.7\% PD-L1+) compared with stage I/II NSCLC (55.9\% PD-L1+) (P=0.049). The lack of statistically significant associations with the majority of the clinicopathological characteristics may be due to the small sample size used in the present study. In a cohort of 331 patients with squamous NSCLC in a previous study, neither PD-L1 nor PD-L2 expression was associated with gender, age, smoking history, tumor size, tumor stage or lymph node metastasis (30). However, PD-L1 expression was marginally associated with tumor stage $(\mathrm{P}=0.059)$ (30). The present study also found that the expressions of PD-1, PD-L1 and PD-L2 were independent of each other, which is consistent with the previous study (30). This independence may suggest that any component of the PD-1-PD-L1/L2 pathway may be upregulated to suppress immune responses in the tumor microenvironment. In addition, the present study indicated that the expression of PD-1, PD-L1 and PD-L2 was not associated with the survival of the patient. In a meta-analysis of 9 studies that included 1,550 NSCLC patients, PD-L1 expression was associated with differentiation status, but not with gender, smoking status, histology, tumor stage or lymph node status (31). These findings suggest that PD-L1 may have limited use for predicting prognosis.

The present study provides essential information regarding the expression of PD-1, PD-L1 and PD-L2 in patients with NSCLC, which may be useful for guiding future treatment with Keytruda ${ }^{\circledR}$ and Opdivo ${ }^{\circledR}$. Given the unsatisfactory clinical outcomes with current therapies, the adoption of immunotherapy may help to improve the survival rate of our patients.

\section{Acknowledgements}

Dr Zongbing You was supported partially by National Institutes of Health (Bethesda, MD, USA; grant nos. P20GM103518 and R01CA174714), Department of Defense (Fort Detrick, MD, USA; grant nos. W81XWH-14-1-0050, W81XWH-14-1-0149, W81XWH-14-1-0458 and W81XWH15-1-0444), the Developmental Fund of Tulane Cancer Center, Louisiana Cancer Research Consortium Fund and Tulane's Institute of Integrated Engineering for Health and Medicine (New Orleans, LA, USA; grant no. TI2EHM). Dr Lunxu Liu was partially supported by National Natural Science Foundation of China (Beijing, China; grant nos. NSFC 81,172,236, 'The mechanism of TAMs activation in lung cancer and a novel immunotherapy' and NSFC 81,372,505, 'The role of IL-17 in formation and progression of primary lung cancer and the underlying molecular mechanisms') and the Key Science and Technology Program of Sichuan Province (Chengdu, China; grant no., 2013SZ0005). Dr Jiandong Mei was a visiting scholar at Tulane University School of Medicine sponsored by the China Scholarship Council (Beijing, China; grant no., 201,406,240,145).

\section{References}

1. Siegel RL, Miller KD and Jemal A: Cancer statistics, 2015. CA Cancer J Clin 65: 5-29, 2015.

2. Chen W, Zhang S and Zou X: Evaluation on the incidence, mortality and tendency of lung cancer in China. Thoracic Cancer 1: 35-40, 2010.

3. Torre LA, Bray F, Siegel RL, Ferlay J, Lortet-Tieulent J and Jemal A: Global cancer statistics, 2012. CA Cancer J Clin 65: 87-108, 2015

4. Ledford H: Cancer treatment: The killer within. Nature 508: 24-26, 2014.

5. Kantoff PW, Higano CS, Shore ND, Berger ER, Small EJ, Penson DF, Redfern CH, Ferrari AC, Dreicer R, Sims RB, et al: Sipuleucel-T immunotherapy for castration-resistant prostate cancer. N Engl J Med 363: 411-422, 2010.

6. Hodi FS, O'Day SJ, McDermott DF, Weber RW, Sosman JA, Haanen JB, Gonzalez R, Robert C, Schadendorf D, Hassel JC, et al: Improved survival with ipilimumab in patients with metastatic melanoma. N Engl J Med 363: 711-723, 2010.

7. Harvey RD: Immunologic and clinical effects of targeting of pd-1 in lung cancer. Clin Pharmacol Ther: 2014.

8. Topalian SL, Hodi FS, Brahmer JR, Gettinger SN, Smith DC, McDermott DF, Powderly JD, Carvajal RD, Sosman JA, Atkins MB, et al: Safety, activity, and immune correlates of anti-pd-1 antibody in cancer. N Engl J Med 366: 2443-2454, 2012.

9. Brahmer JR, Tykodi SS, Chow LQ, Hwu WJ, Topalian SL, Hwu P, Drake CG, Camacho LH, Kauh J, Odunsi K, et al: Safety and activity of anti-pd-11 antibody in patients with advanced cancer. N Engl J Med 366: 2455-2465, 2012.

10. Lipson EJ, Sharfman WH, Drake CG, Wollner I, Taube JM, Anders RA, Xu H, Yao S, Pons A, Chen L, et al: Durable cancer regression off-treatment and effective reinduction therapy with an anti-pd-1 antibody. Clin Cancer Res 19: 462-468, 2013.

11. Hamid O, Robert C, Daud A, Hodi FS, Hwu WJ, Kefford R, Wolchok JD, Hersey P, Joseph RW, Weber JS, et al: Safety and tumor responses with lambrolizumab (anti-pd-1) in melanoma. N Engl J Med 369: 134-144, 2013.

12. Wolchok JD, Kluger H, Callahan MK, Postow MA, Rizvi NA, Lesokhin AM, Segal NH, Ariyan CE, Gordon RA, Reed K, et al: Nivolumab plus ipilimumab in advanced melanoma. N Engl J Med 369: 122-133, 2013.

13. Robert C, Schachter J, Long GV, Arance A, Grob JJ, Mortier L, Daud A, Carlino MS, McNeil C, Lotem M, et al: Pembrolizumab versus ipilimumab in advanced melanoma. N Engl J Med 372: 2521-2532, 2015.

14. Garon EB, Rizvi NA, Hui R, Leighl N, Balmanoukian AS Eder JP, Patnaik A, Aggarwal C, Gubens M, Horn L, et al: Pembrolizumab for the treatment of non-small-cell lung cancer. N Engl J Med 372: 2018-2028, 2015.

15. Herbst RS, Soria JC, Kowanetz M, Fine GD, Hamid O, Gordon MS, Sosman JA, McDermott DF, Powderly JD, Gettinger SN, et al: Predictive correlates of response to the anti-pd-11 antibody mpdl3280a in cancer patients. Nature 515: 563-567, 2014.

16. Cha E, Wallin J and Kowanetz M: Pd-11 inhibition with mpdl3280a for solid tumors. Semin Oncol 42: 484-487, 2015.

17. Ishida Y, Agata Y, Shibahara K and Honjo T: Induced expression of pd-1, a novel member of the immunoglobulin gene superfamily, upon programmed cell death. EMBO J 11: 3887-3895, 1992.

18. Nishimura H, Minato N, Nakano T and Honjo T: Immunological studies on pd-1 deficient mice: Implication of pd-1 as a negative regulator for b cell responses. Int Immunol 10: 1563-1572, 1998.

19. Nishimura H, Nose M, Hiai H, Minato $\mathrm{N}$ and Honjo T: Development of lupus-like autoimmune diseases by disruption of the pd-1 gene encoding an itim motif-carrying immunoreceptor. Immunity 11: 141-151, 1999. 
20. Freeman GJ, Long AJ, Iwai Y, Bourque K, Chernova T, Nishimura H, Fitz LJ, Malenkovich N, Okazaki T, Byrne MC, et al: Engagement of the pd-1 immunoinhibitory receptor by a novel b7 family member leads to negative regulation of lymphocyte activation. J Exp Med 192: 1027-1034, 2000.

21. Dong H, Zhu G, Tamada K and Chen L: B7-h1, a third member of the b7 family, co-stimulates t-cell proliferation and interleukin-10 secretion. Nat Med 5: 1365-1369, 1999.

22. Latchman Y, Wood CR, Chernova T, Chaudhary D, Borde M, Chernova I, Iwai Y, Long AJ, Brown JA, Nunes R, et al: Pd-12 is a second ligand for pd-1 and inhibits t cell activation. Nat Immunol 2: 261-268, 2001

23. Tseng SY, Otsuji M, Gorski K, Huang X, Slansky JE, Pai SI, Shalabi A, Shin T, Pardoll DM and Tsuchiya H: B7-dc, a new dendritic cell molecule with potent costimulatory properties for t cells. J Exp Med 193: 839-846, 2001.

24. Okazaki T and Honjo T: Pd-1 and pd-1 ligands: From discovery to clinical application. Int Immunol 19: 813-824, 2007.

25. Dong H, Strome SE, Salomao DR, Tamura H, Hirano F, Flies DB, Roche PC, Lu J, Zhu G, Tamada K, et al: Tumor-associated b7-h1 promotes t-cell apoptosis: A potential mechanism of immune evasion. Nat Med 8: 793-800, 2002.
26. Keir ME, Butte MJ, Freeman GJ and Sharpe AH: Pd-1 and its ligands in tolerance and immunity. Annu Rev Immunol 26: 677-704, 2008.

27. Sharpe AH and Freeman GJ: The b7-cd28 superfamily. Nat Rev Immunol 2: 116-126, 2002.

28. Travis WD, Brambilla E, Muller-Hermelink HK and Harris CC (eds): World Health Organization Classification of Tumours. Pathology and Genetics of Tumours of the Lung, Pleura, Thymus and Heart. Lyon, IARC Press, pp9-11, 2004.

29. Allred DC, Clark GM, Elledge R, Fuqua SA, Brown RW, Chamness GC, Osborne CK and McGuire WL: Association of p53 protein expression with tumor cell proliferation rate and clinical outcome in node-negative breast cancer. J Natl Cancer Inst 85: 200-206, 1993.

30. Kim MY, Koh J, Kim S, Go H, Jeon YK and Chung DH: Clinicopathological analysis of pd-11 and pd-12 expression in pulmonary squamous cell carcinoma: Comparison with tumor-infiltrating t cells and the status of oncogenic drivers. Lung Cancer 88: 24-33, 2015.

31. Pan ZK, Ye F, Wu X, An HX and Wu JX: Clinicopathological and prognostic significance of programmed cell death ligand1 (pd-11) expression in patients with non-small cell lung cancer: A meta-analysis. J Thorac Dis 7: 462-470, 2015. 